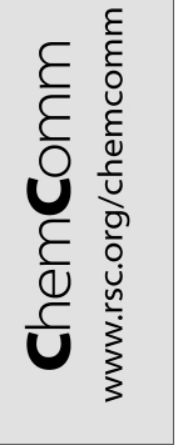

\title{
Hydroformylation in fluorous solvents $\dagger$
}

\author{
Douglas F. Foster, ${ }^{a}$ Dave J. Adams, ${ }^{b}$ David Gudmunsen, ${ }^{b}$ Alison M. Stuart, ${ }^{b}$ Eric G. Hope $^{b}$ and David \\ J. Cole-Hamilton ${ }^{a}$ \\ ${ }^{a}$ Catalyst Evaluation and Optimisation Service, School of Chemistry, University of St. Andrews, St. \\ Andrews, Fife, Scotland, UK KY16 9ST.E-mail: djc@st-and.ac.uk \\ ${ }^{b}$ Department of Chemistry, University of Leicester, Leicester, UK LE1 7RH
}

Received (in Cambridge, UK) 5th November 2001, Accepted 22nd January 2002

First published as an Advance Article on the web 6th March 2002

Triaryl-phosphines and -phosphites bearing fluorous ponytails give high rates, good linear selectivity and good retention of catalyst in the fluorous phase during hydroformylation of alkenes in fluorous solvents.

The formation of long chain linear aldehydes by hydroformylation of terminal alkenes is a very important industrial process in the production of plasticisers, soaps and detergents. $^{1,2}$ If the problem of catalyst separation could be overcome, rhodium based catalysts would be preferred over the currently used cobalt because of the milder operating conditions they require and their better selectivity to the desired linear products. ${ }^{1,2}$ A particularly promising approach to the separation involves reactions in the fluorous biphase. Horváth and coworkers first introduced the concept of carrying out such reactions in a mixture of organic (often toluene) and perfluorinated (often perfluoromethylcyclohexane) solvents, which are immiscible at room temperature. ${ }^{3,4}$ The catalyst is designed to be preferentially soluble in the fluorous phase and the product is contained in the organic phase. Phase separation allows the ready recovery of the product, whilst the catalyst remains in the reactor. The advantage of this system over aqueous biphasic systems ${ }^{5}$ is that a single phase is formed on heating, so the catalyst and substrate are in intimate contact, but phase separation occurs rapidly on cooling. Horváth and coworkers used $\mathrm{P}\left(\mathrm{CH}_{2} \mathrm{CH}_{2} \mathrm{C}_{6} \mathrm{~F}_{13}\right)_{3}$ as the ligand for hydroformylation and showed that a system could be developed that could be used 9 times with loss of only $4.2 \%$ of the rhodium (i.e.

$\dagger$ Electronic supplementary information (ESI) available: typical experimental details. See http:// www.rsc.org/suppdata/cc/b1/b110061k/ an average of $0.45 \%$ per run or $120 \mu \mathrm{g}$ (mol of aldehyde) $)^{-1} .4$ However, good linear selectivities could only be obtained if very large excesses (total concentration) of the expensive fluorous ligand were employed.

We now report that triaryl-phosphines or -phosphites containing fluorous ponytails can give higher rates and linear selectivities, particularly if the organic co-solvent (toluene) is omitted.

Our initial ligand screening programme suggested that rhodium complexes of $\mathrm{P}\left(\mathrm{O}-4-\mathrm{C}_{6} \mathrm{H}_{4} \mathrm{C}_{6} \mathrm{~F}_{13}\right)_{3}{ }^{6}$ could give good linear: branched $(1: b)$ ratios even when used in low concentration, so we sought to optimize its performance. The results are shown in Table 1. $†$ In toluene-perfluoro-1,3-dimethylcyclohexane $(1: 1)$, the activity is high even at low $\mathrm{Rh}\left(2 \mathrm{mmol} \mathrm{dm}^{-3}\right)$ and ligand concentrations $\left(6 \mathrm{mmol} \mathrm{dm}^{-3}\right) \neq$ and increases with temperature (experiments $3-5$ ), whilst the $1: \mathrm{b}$ ratio is much higher than that obtained with $\mathrm{P}(\mathrm{OPh})_{3}$ (experiment 1) or $\mathrm{PPh}_{3}$ (experiment 2) under the same conditions in toluene or tolueneperfluoro-1,3-dimethylcyclohexane. This higher $1: \mathrm{b}$ ratio arises largely because of a decrease of branched aldehyde at the expense of isomerised alkene, and there is only a marginal increase in the selectivity towards the desired linear aldehyde. The 1 : b ratio decreases somewhat with increasing temperature, suggesting that ligand decomposition or reaction with the product aldehyde may be occurring. This is confirmed by the much increased leaching of both $\mathrm{Rh}$ and phosphorus into the organic phase at the higher temperatures. $\$$

Omitting toluene from the system leads to improvements in the system such that the rate, the $1: b$ ratio and the selectivity to linear aldehyde are all increased (experiments 6-8). In addition, the leaching of rhodium and phosphorus from the fluorous

Table 1 Hydroformylation of oct-1-ene at $20 \mathrm{bar} \mathrm{CO} / \mathrm{H}_{2}(1: 1)$

\begin{tabular}{|c|c|c|c|c|c|c|c|c|c|c|c|c|c|c|}
\hline Expt. & Ligand & Solv. ${ }^{a}$ & $\begin{array}{l}{[\mathrm{Rh}]^{b}} \\
/ \mathrm{mmol} \\
\mathrm{dm}^{-3}\end{array}$ & $\begin{array}{l}{[\mathrm{P}]^{b}} \\
/ \mathrm{mmol} \\
\mathrm{dm}^{-3}\end{array}$ & $T /{ }^{\circ} \mathrm{C}$ & $\begin{array}{l}\text { Time/ } \\
\text { min }\end{array}$ & $\begin{array}{l}\text { Isom. }{ }^{c} \\
1 \%\end{array}$ & $\begin{array}{l}\text { Conv. }{ }^{d} \\
1 \%\end{array}$ & $\begin{array}{l}\text { Lineare }^{e} \\
1 \%\end{array}$ & $1: b^{f}$ & $\begin{array}{l}\text { Rate const }{ }^{g} \text {. } \\
/ \mathrm{s}^{-1}\end{array}$ & $\begin{array}{l}\text { TOF- } \\
(\mathrm{I})^{h} / \mathrm{h}^{-1}\end{array}$ & $\begin{array}{l}\mathrm{Rh}_{\text {loss }}^{i} / \% \\
\text { loaded (mg } \\
\text { mol } \\
\text { aldehyde }^{-1} \text { ) }\end{array}$ & $\begin{array}{l}\text { Phosphine } \\
\text { loss } i / \% \\
\text { loaded (mg } \\
\text { mol } \\
\left.\text { aldehyde }^{-1}\right)\end{array}$ \\
\hline 1 & $\mathrm{P}(\mathrm{OPh})_{3}$ & $\mathrm{~T}$ & 2.0 & 6.0 & 70 & 30 & 3.9 & 97.6 & 64.0 & $2.2(1.9)$ & $2.6 \times 10^{-3 j}$ & 4700 & & \\
\hline 2 & $\mathrm{PPh}_{3}$ & $\mathrm{~T}$ & 10.0 & 30.0 & 70 & 30 & 0.7 & 97.9 & 72.3 & $3.0(2.9)$ & $3.0 \times 10^{-3 j}$ & 1100 & & \\
\hline 3 & 1 & $\mathrm{~T} / \mathrm{F} 1$ & 2.0 & 6.0 & 60 & 60 & 13.0 & 96.9 & 69.2 & $4.8(2.5)$ & $8.7 \times 10^{-4}$ & 2000 & 9.7 (15.7) & $21.8(31.8)$ \\
\hline 4 & $\mathbf{1}$ & $\mathrm{T} / \mathrm{F} 1$ & 2.0 & 6.0 & 70 & 60 & 12.7 & 96.1 & 66.7 & $4.1(2.3)$ & $1.4 \times 10^{-3}$ & 3200 & $38.9(62.9)$ & $47.4(69.1)$ \\
\hline 5 & 1 & $\mathrm{~T} / \mathrm{F} 1$ & 2.0 & 6.0 & 80 & 60 & 16.3 & 96.4 & 63.6 & $4.0(2.0)$ & $2.5 \times 10^{-3}$ & 5700 & $54.3(87.7)$ & $60.1(87.8)$ \\
\hline 6 & 1 & $\mathrm{~F} 1$ & 2.0 & 6.0 & 60 & 60 & 12.4 & 97.6 & 75.2 & $7.8(3.4)$ & $1.3 \times 10^{-3}$ & 3000 & $6.4(10.3)$ & $9.6(14.0)$ \\
\hline 7 & 1 & $\mathrm{~F} 1$ & 2.0 & 6.0 & 70 & 30 & 13.8 & 97.5 & 73.8 & $7.8(3.2)$ & $3.5 \times 10^{-3}$ & 8000 & $6.3(10.2)$ & $10.1(14.7)$ \\
\hline 8 & 1 & $\mathrm{~F} 1$ & 2.0 & 6.0 & 80 & 30 & 15.6 & 96.6 & 69.4 & $6.3(2.6)$ & $6.8 \times 10^{-3}$ & 15600 & $5.1(8.2)$ & $11.7(17.1)$ \\
\hline 9 & 1 & $\mathrm{~F} 1$ & 10.0 & 30.0 & 60 & 45 & 13.7 & 97.1 & 75.6 & $9.9(3.6)$ & $1.9 \times 10^{-3}$ & 870 & $2.6(20.6)$ & $3.9(28.6)$ \\
\hline 10 & 2 & $\mathrm{~F} 2$ & 2.0 & 20.0 & 70 & 90 & 3.7 & 97.7 & 80.9 & $6.3(4.9)$ & $1.9 \times 10^{-3}$ & 4400 & $0.05(0.08)$ & $3.3(15.9)$ \\
\hline 11 & 2 & $\mathrm{~F} 2$ & 2.0 & 20.0 & 80 & 30 & 3.1 & 97.9 & 77.8 & $4.7(3.9)$ & $5.9 \times 10^{-3}$ & 13500 & $0.23(0.38)$ & $5.0(24.1)$ \\
\hline 12 & 2 & $\mathrm{~F} 2$ & 2.0 & 20.0 & 90 & 30 & 4.1 & 97.9 & 76.1 & $4.4(3.6)$ & $1.3 \times 10^{-2}$ & 29800 & $0.33(0.54)$ & $3.8(18.6)$ \\
\hline \multicolumn{15}{|c|}{ 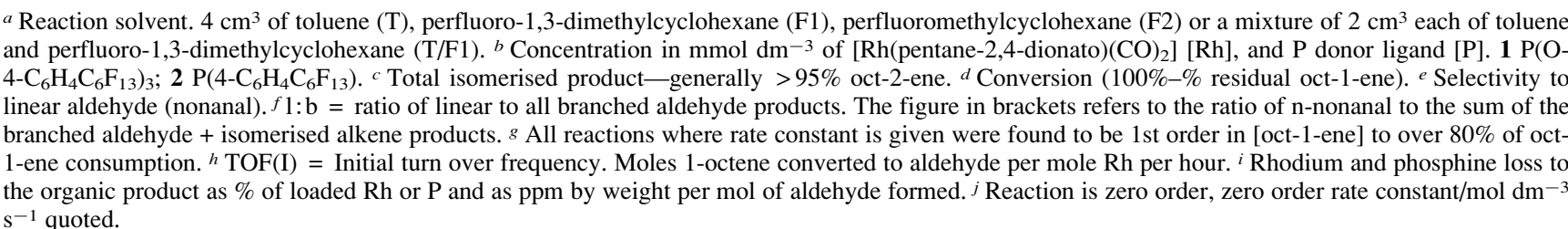 } \\
\hline
\end{tabular}


phase are greatly reduced and vary little as the temperature is increased, suggesting that the stability of the catalyst and ligand is greatly increased in the absence of toluene. In the absence of toluene the polar aldehyde phase separates as it forms, greatly reducing the possibility for destructive reactions between the phosphite and aldehyde. Increasing the concentration of the catalyst and the ligand (experiment 9) increases the rate somewhat, but also increases the $1: b$ ratio, mainly again because more isomerised alkene is produced at the expense of branched aldehyde, although the best selectivity to linear aldehyde $(75.6 \%)$ using this ligand is obtained with the higher catalyst and ligand loading at $60{ }^{\circ} \mathrm{C}$ (experiment 9). The leaching, in terms of percentage lost to the organic phase is also lowest at $2.6 \%$ (20.6 mg Rh (mol of aldehyde) ${ }^{-1}$ ) and 3.9\% (28.6 mg P (mol of aldehyde) $)^{-1}$ ). We have noted similar high 1:b ratios when using triaryl-phosphites for reactions carried out in supercritical fluids ${ }^{7}$ or ionic liquid-supercritical fluid biphasic systems. ${ }^{8}$

Given the problems of catalyst-ligand instability experienced with the fluorous derivatised phosphite, we investigated the use of the analogous phosphine, $\mathrm{P}\left(4-\mathrm{C}_{6} \mathrm{H}_{4} \mathrm{C}_{6} \mathrm{~F}_{13}\right)_{3},{ }^{6}$ which gives high rates for hydroformylation in $\mathrm{scCO}_{2},{ }^{9}$ again using only the fluorous solvent, although in this case perfluoromethylcyclohexane (experiments 10-12). This ligand proved to be much more stable than the phosphite and gave good rates and linear selectivities with little evidence for decomposition up to $80^{\circ} \mathrm{C}$, although increased $\mathrm{Rh}$ leaching occurred when reactions were carried out at $90{ }^{\circ} \mathrm{C}$ (experiment 12). The best results were obtained with a rhodium loading of $2 \mathrm{mmol} \mathrm{dm}^{-3}$ and a P:Rh ratio of 10:1 (experiment 10). Even at this ratio, the phosphine concentration is only $20 \mathrm{mmol} \mathrm{dm}{ }^{-3}$, compared with the loading of $152 \mathrm{mmol} \mathrm{dm}^{-3}$ used by Horváth and co-workers to obtain a similar $1: \mathrm{b}$ ratio with their phosphine, ${ }^{4}$ and a loading of 200-300 mmol dm $\mathrm{dm}^{-3}$ used in commercial systems employing $\mathrm{PPh}_{3} .{ }^{1}$ The results obtained under these conditions, presented diagrammatically in Fig. 1, show that a linear selectivity over $80 \%$ can be obtained at a high rate and with excellent retention of rhodium $\left(99.95 \%\right.$, loss of $0.08 \mathrm{mg} \mathrm{Rh}$ (mol aldehyde) ${ }^{-1}$ ) and phosphorus $\left.(96.7 \% \text {, loss of } 15.9 \mathrm{mg} \text { (mol aldehyde) })^{-1}\right)$ in the fluorous phase. These figures are compared with results obtained by Horváth and co-workers ${ }^{4}$ and with results from publications and patents that are closely related to the commercial systems $\mathrm{s}^{1,10,11}$ in Fig. 2. This comparison shows that at similar rhodium concentrations and pressures to those used commercially, but at much lower temperatures and phosphine loadings (important because of the cost of the fluorous phosphine), experiment 10 gives much higher rates (expected because of the lower phosphine loading) and comparable selectivities (1:b and linear aldehyde), especially when it is remembered that the commercial system uses propene, which cannot isomerise and in experiment $10,3.7 \%$ of the selectivity is lost to alkene isomerisation. It seems that the major advantage in our system over the commercial systems is that high linear selectivities can be obtained at much lower phosphine loading and hence high rates do not need to be compromised.

Horváth and co-workers used a lower catalyst loading but higher [phosphine], so it is not surprising that their rate was lower. Their selectivity was also lower but the leaching of rhodium per mol of aldehyde produced is similar in the two systems. Although, they did not measure phosphorus leaching

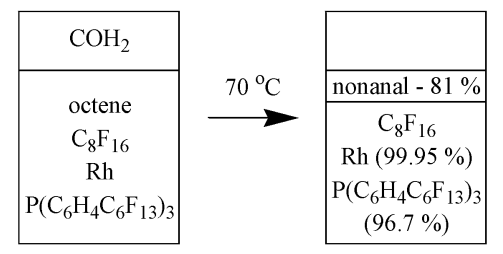

Fig. 1 Diagrammatic representation of experiment 10; the catalytic hydroformylation of oct-1-ene in perfluorocyclohexane catalysed by a rhodium complex of $\mathrm{P}\left(4-\mathrm{C}_{6} \mathrm{H}_{4} \mathrm{C}_{6} \mathrm{~F}_{13}\right)_{3}$.

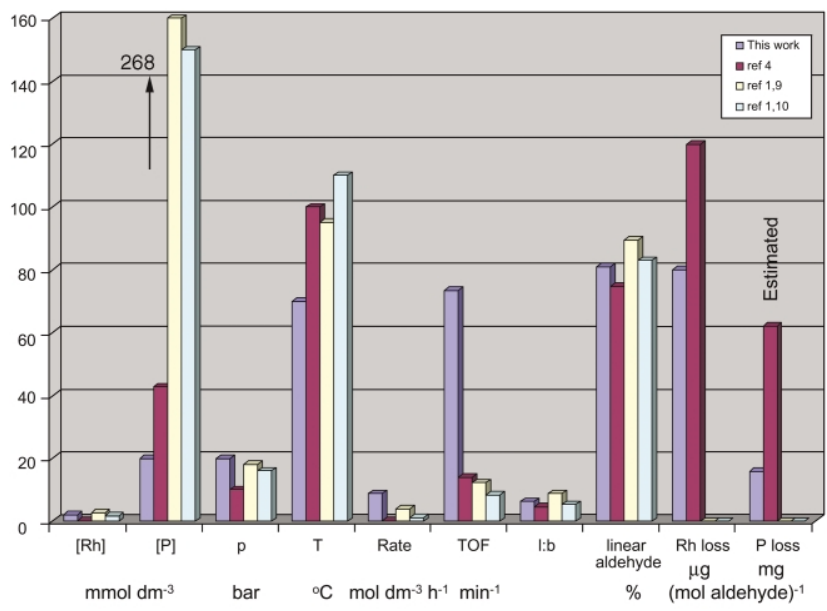

Fig. 2 Comparison between results obtained in this work (experiment 10) for hydroformylation of oct-1-ene with those reported in ref. 4 (dec-1-ene) and those from patents and publications that are closely related to the commercial processes for propene run by Union Carbide (UCC) $)^{1,2,10}$ and BASF. ${ }^{1,2,11}$

they acknowledged that it was significant; we have estimated it at $3 \%$ per reaction (i.e. comparable to the losses we observe) based on the change in 1:b ratio and rate that they observed.

We conclude that triaryl-phosphines or phosphites bearing fluorous ponytails can give superior performance in terms of reaction rate, linear selectivity, and retention into the fluorous phase at lower ligand loadings than trialkylphosphine analogues. Extra advantages in terms of all of these parameters are obtained by working purely in the fluorous phase, which offers the added advantage that the alkene is completely miscible with the solvent, whilst the aldehyde phase separates. In addition, there are considerable advantages to the processing of the product since it does not have to be separated from an organic solvent such as toluene.

We thank the Royal Society (EGH and AMS) and the EPSRC for a Postdoctoral Fellowship (DJA) and for funding to use the Catalyst Evaluation and Optimisation Service (CATS). We are indebted to Ed McCurdy, Agilent Technologies UK Ltd. for carrying out the ICPMS analyses.

\section{Notes and references}

\$Low ligand concentrations are essential for the successful use of expensive fluorinated ligands.

$\S$ Since the separation is always carried out at room temperature, a stable catalyst at a given concentration of ligand and metal should give the same amount of leaching regardless of the reaction temperature.

1 C. D. Frohling and C. W. Kohlpaintner, in Applied Homogeneous Catalysis with Organometallic Compounds, ed. B. Cornils and W. A. Herrmann, VCH, Weinheim, 1996.

2 P. W. N. M. Van Leeuwen and C. Claver, Rhodium catalysed hydroformylation, Kluwer, Dordrecht, 2000.

3 I. T. Horváth and J. Rabái, Science, 1994, 266, 72.

4 I. T. Horváth, G. Kiss, R. A. Cook, J. E. Bond, P. A. Stevens, J. Rabái and E. J. Mozeleski, J. Am. Chem. Soc., 1998, 120, 3133.

5 B. Cornils, in Applied Homogenous Catalysis with Organometallic Compounds, ed. B. Cornils and W. A. Herrmann, VCH, Weinheim, 1996.

6 P. Bhattacharyya, D. Gudmunsen, E. G. Hope, R. D. W. Kemmitt, D. R. Paige and A. M. Stuart, J. Chem. Soc., Perkin Trans. 1, 1997, 3609.

7 M. F. Sellin and D. J. Cole-Hamilton, J. Chem. Soc., Dalton Trans., 2000, 11, 1681

8 M. F. Sellin, P. B. Webb and D. J. Cole-Hamilton, Chem. Commun., 2001, 781.

9 A. M. B. Osuna, W. P. Chen, E. G. Hope, R. D. W. Kemmitt, D. R. Paige, A. M. Stuart, J. L. Xiao and L. J. Xu, J. Chem. Soc., Dalton Trans., 2000, 4052.

10 E. A. V. Brewester and R. L. Pruett, US Pat., 1970, 4,247,486, Chem. Abstr., 1976, 84, 24271.

11 P. Zehner, H. Hoffmann, W. Richter, D. Stuetzer, M. Strohmeyer, W. Helmut and E. Weippert, Eur. Pat., 1987, 254,180. 